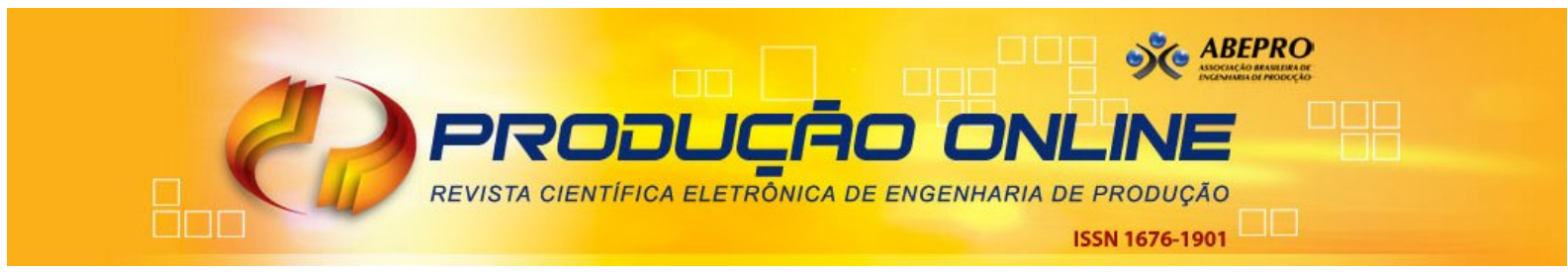

\title{
AVALIAÇÃO DOS INDICADORES DE ACIDENTES DE TRABALHO COMO PROPOSTA DE INTERVENÇÕES ERGONÔMICAS EM UM ABATEDOURO DE FRANGOS
}

\section{EVALUATION OF ACCIDENTS INDICATORS AS ERGONOMIC INTERVENTION PROPOSITION IN A CHICKEN SLAUGHTERHOUSE}

\author{
Fabiano Takeda* E-mail: takeda.f@bol.com.br \\ Eugenio Andrés Díaz Merino* E-mail: eugenio.merino@ufsc.br \\ Giselle Schmidt Alves Díaz Merino* E-mail: gisellemerino@gmail.com \\ Antônio Renato Pereira Moro* E-mail: renato.moro@ufsc.br \\ Natália Fonseca Dias* E-mail: nataliaadias@hotmail.com \\ *Universidade Federal de Santa Catarina (UFSC), Florianópolis, SC.
}

\begin{abstract}
Resumo: A indústria frigorífica faz do Brasil um dos principais produtores e exportadores mundiais de carne. Nesta perspectiva, este setor mantem-se na busca constante pela competitividade, sendo que as atividades nas indústrias são intensificadas para alcançar maior produtividade, resultando em doenças ocupacionais e riscos de acidentes. Para propor medidas que contribuam na redução de acidentes de trabalho em abatedouros de frangos, esta pesquisa tem como objetivo avaliar os indicadores de acidentes e propor demandas de intervenções ergonômicas com base nos indicadores de acidentes que ocorreram nos anos de 2012, 2013 e 2014 em um abatedouro de frangos localizado na região de São José - S.C. O estudo trata de uma pesquisa de campo com análise documental e utilização do método indutivo. Os dados foram avaliados quantitativamente utilizando-se de planilhas eletrônicas e gráficos. Os resultados apontam que do total de 161 acidentes avaliados, os com cortes foram os que apresentaram o maior número de casos. O agente causador que mais gerou acidentes foi o uso de facas e a parte do corpo mais atingida nos acidentes foi os membros superiores. Os resultados apontam que o abatedouro apresenta demandas de intervenções ergonômicas para adequação das condições de trabalho com enfoque na redução de acidentes de trabalho.
\end{abstract}

Palavras-chave: Intervenção. Ergonomia. Abatedouro. Acidentes.

Abstract: The slaughterhouse industry makes Brazil a major producer and exporter of meat. In this perspective, this industry keeps in constant pursuit of competitiveness, and the activities within this sector are intensified to achieve greater productivity which results in occupational diseases and injury hazards. In order to propose measures that can contribute to the reduction of occupational accidents in poultry slaughterhouse, this research aims to evaluate and propose demands of ergonomic interventions based on accident numbers that occurred in the years 2012, 2013 and 2014 in a poultry slaughterhouse located in the region of São José - SC. The study is a field research with documental analysis and with the use of the inductive method. The data were evaluated quantitatively using spreadsheet and graphics. The results show that the total of 161 accidents assessed, the accidents with cuts were those with the highest number of cases. The causative agent that generated most accidents was the use of knives and the most affected part of the body was the upper limbs. The results show that the slaughterhouse presents demands of ergonomic interventions to adapt working conditions with a focus on reducing workplace accidents.

Keywords: Intervention. Ergonomics. Slaughterhouse. Accidents.

Revista Produção Online, Florianópolis, SC, v.16, n. 1, p. 182-209, jan./mar. 2016. 


\section{INTRODUÇÃO}

A indústria frigorífica e o complexo de carnes fazem hoje do Brasil um dos principais exportadores mundiais de produtos de origem animal (MARRA, SOUZA, CARDOSO, 2013). De acordo com Instituto Brasileiro de Geografia e Estatística IBGE, o número de abatedouros vem aumentando crescentemente em todo o território nacional, apenas em 2014, os últimos levantamentos a respeito deste cenário identificaram 1.172 empresas do ramo de abate de suínos, aves e de outros pequenos animais (IBGE, 2014).

O aumento da demanda do mercado de carnes, inclusive internacional, tem pressionado a chamada competitividade e, nesta perspectiva, as atividades dentro das indústrias são intensificadas na busca de maior produtividade e no alcance da qualidade dos alimentos de origem animal, resultando aos trabalhadores fadiga física, mental e psíquica e acarretando doenças ocupacionais e diversos riscos de acidentes, com grande enfoque nos riscos ergonômicos (DEFANI, 2007; PEGATIN, 2008; REIS, 2012).

Diante deste cenário, ressalta-se que o Brasil é um dos países com o maior número de acidentes e doenças de trabalho segundo dados da Organização Internacional do Trabalho (OIT, 2015). De acordo com Carpes Jr e Sell (2003), os acidentes de trabalho podem ocasionar lesões, mortes, processos judiciais e danos materiais diversos.

Em relação aos abatedouros brasileiros listados conforme a Classificação Nacional de Atividades Econômicas - CNAE com número de classificação 1012 foi registrado, no último anuário estatístico de acidentes, um total de 10.073 casos de acidentes nas indústrias frigoríficas em todo o território nacional dividido entre acidentes classificados como típico, trajeto e doença ocupacional (MINISTÉRIO DA PREVIDÊNCIA SOCIAL, 2015).

Fica evidente nos resultados dos anuários estatísticos de abatedouros que não apenas o número de empresas e empregados cresce constantemente, mas também o número de acidentes e doenças relacionadas ao trabalho em abatedouros.

As estimativas nacionais são de que $23 \%$ da mão de obra do setor de abatedouros estão afastadas ou no aguardo de decisões judiciais em função de Revista Produção Online, Florianópolis, SC, v.16, n. 1, p. 182-209, jan./mar. 2016. 
acidentes e doenças relacionados ao trabalho (MINISTÉRIO DO TRABALHO E EMPREGO, 2015).

Para contribuir com as condições apresentadas nos dados oficiais de acidentes e doenças relacionadas ao trabalho, Sarda et al. (2009) demonstram em sua pesquisa que as condições de trabalho encontradas em frigoríficos e abatedouros causam problemas relacionados a saúde, conforto, segurança e medicina ocupacional que atendam às necessidades dos trabalhadores. Desta forma, percebe-se a ausência de um sistema preventivo eficiente, que apresente contribuições efetivas para impedir a ocorrência de acidentes e doenças relacionadas ao trabalho.

Além do elevado número de acidentes reconhecidos pelos setores de segurança e medicina dos abatedouros, outro ponto importante a ser destacado é que em muitos casos há omissão da abertura do Comunicado de Acidente e Doença do Trabalho - CAT. Os próprios resultados dos anuários estatísticos de acidentes do Ministério da Previdência Social apresentam que há casos confirmados pelo Nexo Técnico Epidemiológico - NTEP.

Verifica-se, ainda, que há falhas na caracterização de acidentes e doenças por parte das empresas, pois o NTEP caracteriza apenas o Nexo em casos com afastamentos em que o empregado passa por perícia médica do Instituto Nacional do Seguro Social - INSS. Assim, os acidentes que não atendem à quantidade de dias necessários para o afastamento do trabalhador podem ser omitidos pelas empresas, fator este que contribui negativamente para o controle oficial de acidentes e doenças ocupacionais, evidenciando que as ações de controle têm menores chances de serem implantadas com o intuito de reduzir as condições de risco.

Enfim, é possível perceber que os mecanismos preventivos existentes e as ferramentas utilizadas na identificação dos fatores envolvidos na gênese de acidentes e doenças ligados ao trabalho em abatedouros parecem não atender ainda às demandas das organizações e dos trabalhadores.

Conforme as normas de segurança e medicina do Ministério do Trabalho e Emprego, as equipes de segurança e medicina são de caráter obrigatório nas empresas, sendo que, o objetivo de ambas as equipes é buscar a redução ou até mesmo a eliminação dos riscos à saúde e segurança dos trabalhadores. 
Contudo, mesmo com este foco, nota-se a necessidade de se gerenciar todas as condições que possam causar acidentes bem como as condições de risco que possam existir nos ambientes de trabalho. Assim, esta pesquisa tem como objetivo avaliar os indicadores de acidentes para verificar a necessidade de se propor demandas de intervenções ergonômicas para a eliminação, neutralização ou minimização dos riscos de acidentes e doenças conforme números de acidentes que ocorreram nos anos de 2012, 2013 e 2014 em um abatedouro de frangos localizado na região de São José - S.C.

\section{FUNDAMENTAÇÃO TEÓRICA}

\subsection{Ergonomia em Abate e Operações de Processamento de Carnes}

A ergonomia dentro de uma organização contribui para melhorar a eficiência, a confiabilidade e a qualidade dos produtos e das operações industriais assim como a integridade das pessoas no sentido de prevenção de acidentes e de doenças ocupacionais. Tais ações podem ser alcançadas basicamente por três vias: aperfeiçoamento do sistema homem-máquina, organização do trabalho e melhoria das condições de trabalho (IIDA, 2005).

No que diz respeito aos abatedouros, diversos são os riscos de natureza ergonômica e de acidentes para os trabalhadores, uma vez que as atividades em abatedouros-frigoríficos demandam do trabalhador atenção nas operações que são, em sua maioria, de alta produção individual, manuais, rotineiras, fixas e pouco variáveis com ritmo intenso de trabalho, também considerados como trabalho monótono e fatigante, que exige dos trabalhadores movimentos repetitivos e frequente manipulação de instrumentos cortantes (CAMPOAMOR, 2006; DEFANI, 2007; PEGATIN, 2008; SARDA et al., 2009; REIS, 2012).

Os estudos disponíveis na literatura especializada sobre abatedouros no âmbito da ergonomia tanto nacional quanto internacional referem-se a pesquisas voltadas a riscos de acidentes de trabalho, segurança e doenças ocupacionais. (ARMSTRONG et al., 1993; SOMMERICH, MCGLOTHLIN, MARRAS, 1993; FROST, ANDERSEN, NIELSEN, 1998; BAO et al., 2001; JUUL-KRISTENSEN et al., 2002; 
BUSNELLO, DEWES, 2013; HECK, 2013; SUNDSTRUP et al., 2013; SUNDSTRUP et al., 2014; MUSOLIN et al., 2014).

Segundo Silveira e Merlo (2014), os processos de trabalho nos abatedouros têm sido o cenário de dramas e lutas correspondentes às condições de trabalho e à saúde dos trabalhadores. Os autores afirmam ainda que este setor exige a busca por melhores condições no ambiente de trabalho que atendam às necessidades dos trabalhadores e que estes ambientes de trabalho não apresentam riscos à saúde e segurança destes trabalhadores, porém, para mensurar as necessidades dos trabalhadores, torna-se necessário realizar uma avaliação multicausal que considere os diferentes componentes do sistema.

De acordo com Busnello e Dewes (2013), há um elevado número de casos de trabalhadores de abatedouros acometidos por acidentes de trabalho e doenças ocupacionais, principalmente as Doenças Osteomusculares Relacionadas ao Trabalho - DORT, condição esta que tem sido motivo de preocupação para os profissionais de saúde e segurança do trabalho.

Vilela et al. (2012) descreveram em pesquisa realizada em um abatedouro, na qual analisou e avaliou dados de acidentes de 1997 a 2008, que as causas imediatas da maioria dos acidentes de trabalho estavam relacionadas ao manuseio de facas, à realização de força e ao movimento de peso, bem como outras condicionantes do sistema produtivo e do próprio trabalhador acidentado.

Diante deste cenário apresentado pelos autores anteriormente citados, de trabalho nos abatedouros, de ocorrências de lesões, doenças e acidentes ligados ao trabalho, de alta produção individual e de condições do ambiente de trabalho que desfavorecem a execução das atividades com saúde e segurança dos trabalhadores, verifica-se que são indispensáveis ações de prevenção e de intervenções ergonômicas que atendam às demandas das organizações e dos trabalhadores com o intuito de alcançar os objetivos da ergonomia definidos por Wisner (1972) como conhecimento aplicado pelo homem no ambiente de trabalho para busca do máximo conforto, segurança e eficácia.

Programas básicos de ergonomia podem produzir muitos resultados benéficos para as empresas e para os empregados. Geralmente tais programas devem ser adotados pela alta administração, seguida dos níveis hierárquicos abaixo, 
com o intuito de eliminação ou redução de erros no sistema produtivo e principalmente de acidentes e doenças de trabalho.

Ressalta-se que além dos resultados benéficos que a ergonomia pode propiciar aos trabalhadores de abatedouros e para as empresas, a sua implantação por parte das indústrias é de obrigatoriedade conforme as Normas Regulamentadoras de Medicina e Segurança do Trabalho (NRs), em específico na NR-36 direcionada particularmente a abatedouros e frigoríficos e na NR-17 que visa estabelecer parâmetros que permitam a adaptação das condições de trabalho às características psicofisiológicas dos trabalhadores de modo a proporcionar um máximo de conforto, segurança e desempenho eficiente.

Diante os fatores apresentados, tornam-se necessárias ações que intervenham nas condições de trabalho em abatedouros, com foco na eliminação, neutralização ou minimização dos riscos de acidentes e doenças. As ações não devem ser abordadas apenas como um fenômeno à parte ou como um simples produto de uma dada causa, e sim como resultado de interações entre os diferentes componentes do sistema, pois quando o ambiente de trabalho é adequado do ponto de vista funcional, este acaba por corroborar para que as atividades sejam realizadas satisfatoriamente com desempenho, qualidade e eficiência (PIERANTONI et al., 2011 apud SOUZA et al., 2015).

\subsection{Acidentes de Trabalho}

Carpes Jr e Sell (2003) comentam que a palavra acidente está ligada à ideia de acaso ou imprevisto e que nas primeiras discussões sobre acidentes de trabalho, estes foram associados à "casualidade" ou "fatalidade", sendo considerados como consequência natural e irremediável das atividades humanas.

Para compreender o termo acidente de trabalho, é necessário entender seu conceito geral que pode ser descrito conforme o Artigo 19 da Lei no 8213/91 que considera acidente de trabalho como aquele que ocorre pelo exercício do trabalho a serviço da empresa provocando lesão corporal ou perturbação funcional que cause morte ou perda ou redução, permanente ou temporária, da capacidade para o trabalho. Nesta mesma lei caracterizam-se como acidente de trabalho os casos de 
doenças ocupacionais e acidentes de trajeto. Especificamente as doenças ocupacionais são dividas em duas condições: doenças do trabalho e doenças profissionais.

A seguir são apresentadas, conforme definições da ABNT: NBR 14280:2001, as condições que caracterizam acidentes de trabalho, doenças ocupacionais e acidentes de trajeto.

Segundo a ABNT: NBR 14280:2001, o acidente de trabalho inclui tanto ocorrências que podem ser identificadas em relação a um momento determinado, quanto ocorrências ou exposições contínuas ou intermitentes que só podem ser identificadas em termos de período de tempo provável. A lesão pessoal inclui tanto lesões traumáticas e doenças, quanto efeitos prejudiciais mentais, neurológicos ou sistêmicos, resultantes de exposições ou circunstâncias verificadas na vigência do exercício do trabalho. Refere-se ainda que no período destinado a refeição ou descanso, ou por ocasião da satisfação de outras necessidades fisiológicas, no local de trabalho ou durante este, o empregado é considerado no exercício do trabalho, ou seja, qualquer lesão nas circunstâncias descritas será considerada como acidente de trabalho. Outros casos não descritos nesta norma não serão considerados como acidente de trabalho.

A doença ocupacional do trabalho é definida, de acordo com a ABNT: NBR 14280:2001, como doença decorrente do exercício continuado ou intermitente de atividade laborativa capaz de provocar lesão por ação mediata na qual deve admitirse, no caso de ser a lesão uma doença do trabalho, a preexistência de uma ocorrência ou exposição contínua ou intermitente, de natureza acidental, a ser registrada nas estatísticas como acidente. A doença deve, ainda, constar na relação oficial do Ministério do Trabalho e da Previdência Social.

A doença ocupacional profissional, conforme a ABNT: NBR 14280:2001, é a doença causada pelo exercício de atividade específica constante na relação oficial do Ministério do Trabalho e da Previdência Social.

Com relação ao acidente de trajeto, a ABNT: NBR 14280:2001 define que é aquele acidente sofrido pelo empregado no percurso da residência para o local de trabalho ou deste para aquela, qualquer que seja o meio de locomoção, inclusive veículo de propriedade do empregado, desde que não haja interrupção ou alteração 
de percurso por motivo alheio ao trabalho e que, de acordo com a norma entende-se como percurso o trajeto da residência ou do local de refeição para o trabalho ou deste para aqueles, independentemente do meio de locomoção, sem alteração ou interrupção por motivo pessoal, do percurso do empregado. Não havendo limite de prazo estipulado para que o empregado atinja o local de residência, refeição ou trabalho, deve ser observado o tempo necessário compatível com a distância percorrida e o meio de locomoção utilizado para fins de caracterização do acidente.

$\mathrm{Na}$ ocorrência de qualquer um dos casos citados de acidentes, doenças ocupacionais ou acidentes de trajeto, é imprescindível a abertura do Comunicado de Acidente de Trabalho - CAT. Esta comunicação é um documento obrigatório que deve ser emitido para o reconhecimento de um acidente de trabalho ou uma doença ocupacional. Sua fundamentação está no Artigo 22 da Lei no 8213/91 que cita que a empresa deverá comunicar o acidente do trabalho à Previdência Social até $01^{\circ}$ (primeiro) dia útil seguinte ao da ocorrência e, em caso de morte, de imediato.

Para ocorrer a abertura de CAT, os acidentes e doenças devem ser primeiramente reconhecidos pela empresa. O procedimento básico para que isto ocorra é que o trabalhador relate ao serviço de segurança e medicina da empresa, quando houver, ou para o seu superior direto, qualquer condição que caracterize um acidente, ou indícios de possível doença ou acidente de trajeto. A falta de abertura de CAT devido a um acidente ou uma doença pode ocorrer em função do trabalhador ou da empresa.

Do trabalhador devido a não informação de um acidente, ou a falta de uma rotina de exames médicos que possam comprovar a existência de uma doença. Cabe ressaltar que podem ocorrer casos da falta da comunicação do acidente para a empresa devido a o trabalhador sentir-se inseguro em avisar a ocorrência de um acidente no ambiente no trabalho e a falta de comunicação por parte do trabalhador de uma doença ocupacional pode ocorrer devido à falta de exames periódicos que comprovem a existência de uma doença.

Por outro lado, pode ocorrer a falta de emissão de CAT por parte das empresas quando não há o reconhecimento do acidente como uma condição proveniente do ambiente de trabalho ou da atividade exercida pelo trabalhador. 
Nota-se que, em relação à oficialização dos dados quanto à abertura da CAT, podem ocorrer divergências dos números devido a diversos fatores e que apenas alguns deles foram descritos.

\section{PROCEDIMENTOS METODOLÓGICOS}

Esta seção tem como objetivo descrever os métodos utilizados para o desenvolvimento da pesquisa. Inicialmente foi realizada uma pesquisa bibliográfica sobre ergonomia e abatedouros. Seguindo os conceitos metodológicos, foi realizada uma pesquisa de campo com análise documental dos dados dos acidentes de trabalho que ocorreram com funcionários da empresa em estudo.

Segundo Lakatos e Marconi (2007), a pesquisa sempre parte de um tipo de problema, de uma interrogação. Partindo deste conceito proposto pelas autoras, buscou-se com esta pesquisa avaliar os indicadores dos números de acidentes que ocorreram nos anos de 2012, 2013 e 2014 no abatedouro em estudo para posteriormente analisar a necessidade de serem propostas demandas de intervenções ergonômicas que pudessem contribuir efetivamente para a eliminação, neutralização ou minimização dos índices de acidentes em Empresas de Abate e Processamento de Carnes e Derivados.

De acordo com Gil (1989), uma pesquisa, como toda atividade racional e sistemática, tem por objetivo proporcionar soluções aos problemas encontrados, e por isso é necessária quando não se dispõe de informações suficientes para se responder ao problema. Ainda na visão do mesmo autor, a pesquisa a pesquisa pode ser realizada por meio de conhecimentos disponíveis e da utilização cuidadosa de métodos e técnicas científicas desenvolvidas ao longo de um processo que envolve inúmeras fases, desde a formulação do problema até a apresentação dos resultados.

Considerando os conceitos descritos por Gil (1989), a pesquisa foi classificada para realização do trabalho utilizando o método indutivo, na qual partiuse dos conhecimentos disponíveis de indicadores de acidentes para posterior formulação teórica dos conceitos que deram suporte para alcançar os objetivos propostos. 
Quanto ao universo e amostra, a pesquisa foi realizada com os indicadores de acidentes dos anos de 2012, 2013 e 2014 que ocorreram com funcionários de um abatedouro de cortes de frangos, no qual foram avaliados apenas os acidentes típicos, excluindo da avaliação os acidentes de trajeto e as doenças ocupacionais.

Os acidentes de trajeto foram excluídos devido ao baixo número de ocorrências registrado, e à falta de dados no tratamento das investigações, haja vista que, de acordo com o serviço de segurança da empresa, como os acidentes de trajeto envolvem outras pessoas além do trabalhador da empresa e não há ações eficientes, estes dados são apenas analisados e arquivados. Já as doenças ocupacionais foram excluídas em função da falta de documentação legal que comprove a ocorrência das mesmas, pois durante os três anos avaliados não foram reconhecidas aberturas de CAT's de doenças por iniciativa da empresa.

Para a coleta de dados, foram utilizadas planilhas eletrônicas e a avaliação visual dos registros de acidentes de trabalho.

Para a interpretação dos dados coletados, os mesmos foram avaliados quantitativamente, utilizando-se planilhas eletrônicas e gráficos.

\section{DESENVOLVIMENTO}

\subsection{Descrição do Local de Trabalho Pesquisado}

O estudo foi desenvolvido com dados de acidentes de um abatedouro de frangos localizado na região de São José - SC. O quadro atual da empresa é composto de aproximadamente 1200 trabalhadores, divididos em dois turnos de abate e um terceiro turno utilizado para manutenção preventiva e higienização de máquinas e equipamentos. A unidade abate em média 110.000 aves/dia, sendo que o primeiro turno abate 60.000 aves/dia e o segundo turno abate 50.000 aves/dia.

A jornada de trabalho nos setores de produção é de 8h48min/dia, com intervalos de 60 minutos diários para alimentação e pausas de 60 minutos de recuperação psicofisiológicas distribuídas na jornada de trabalho em três pausas de 20 minutos conforme determina a Norma Regulamentadora NR-36 - Segurança e Saúde no Trabalho em Empresas de Abate e Processamento de Carnes e Derivados.

Revista Produção Online, Florianópolis, SC, v.16, n. 1, p. 182-209, jan./mar. 2016. 


\subsection{Acidentes de Trabalho}

Nesta seção são apresentados os resultados da pesquisa quanto ao levantamento das estatísticas de acidentes do abatedouro de frangos em estudo. Vale ressaltar que foram avaliados os acidentes típicos, ou seja, os que ocorrem diretamente nos processos produtivos sem afastamento e com afastamento imediato dos trabalhadores do posto de trabalho. Não foram avaliados os acidentes de trajeto que são aqueles que ocorrem entre a casa e a empresa e vice-versa, acidentes sem abertura de CAT e doenças ocupacionais.

Na Figura 01 estão apresentados os acidentes contabilizados com abertura de CAT entre os anos 2012 e 2014.

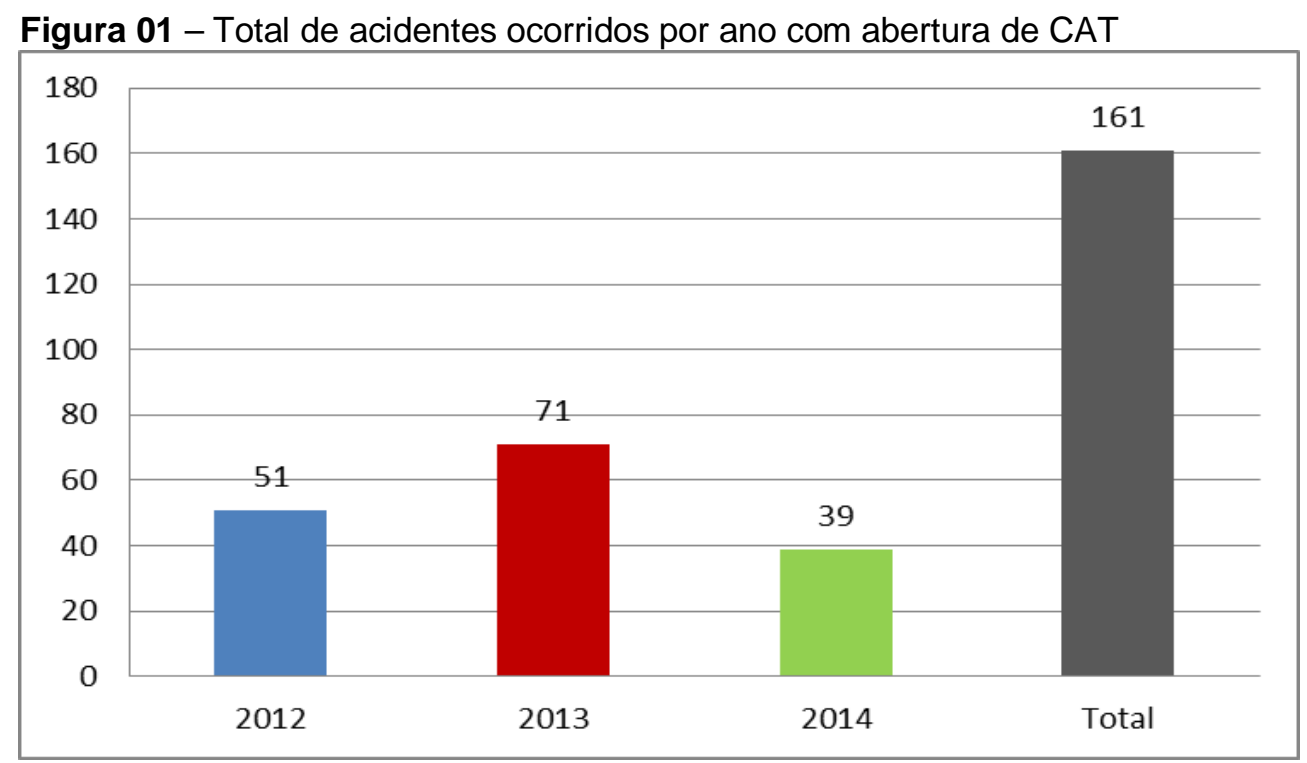

Fonte: Dados do abatedouro (2015)

É possível verificar na Figura 01 que no ano de 2013 houve um acréscimo no número de acidentes em relação ao ano de 2012, e que, no ano de 2014, houve um decréscimo em relação ao ano de 2013. Conforme verificado in loco, os gestores da empresa atribuíram as causas do acréscimo de acidentes no ano de 2013 ao aumento de um turno de trabalho na empresa, o que gradativamente aumentou o número de trabalhadores bem como o número de acidentes.

Porém, em 2014, com um turno a mais em relação ao ano de 2012, os motivos apresentados foram que houve a implantação de programas de gestão de 
segurança do trabalho e principalmente de itens obrigatórios da Norma Regulamentadora NR-36, norma esta de segurança do trabalho específica para abatedouros publicada em 18 de abril de 2013. De acordo com os gestores, inúmeros acidentes deixaram de ocorrer após a implantação dos itens da NR-36 e dos programas de gestão de segurança.

Sendo assim, a pesquisa não demonstrou correlação significativa entre redução dos acidentes, ações realizadas, ambiente e atividades executadas pelos acidentados. Constatou-se que a variável importante na redução dos acidentes foi a implantação dos itens da NR-36, direcionando melhorias no ambiente físico e nas condições organizacionais.

Seguindo a análise dos dados da pesquisa, os 161 registros de acidentes ocorridos durante os três anos avaliados foram estratificados e apresentados por tipo de lesão, conforme mostra Figura 02.

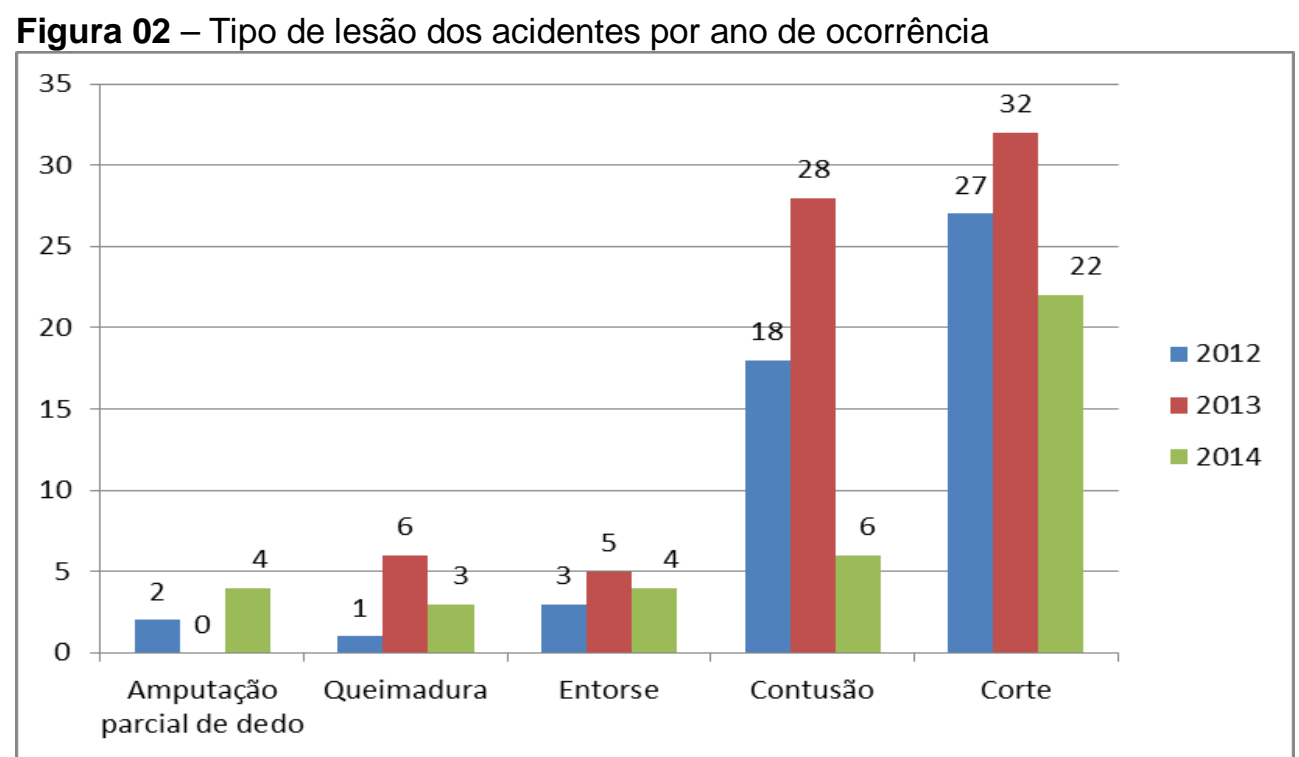

Fonte: Dados do abatedouro (2015)

Verifica-se na Figura 02 que entre as cinco categorias de lesão registradas pela área médica da empresa, ocorreram 81 casos de acidentes por cortes seguidos por 52 casos diagnosticados por contusão, 12 casos por entorse, 10 casos por queimaduras e 6 casos por amputação parcial de dedo.

Em relação aos seis casos de acidentes que ocasionaram amputação parcial de dedo, todos ocorreram em máquinas e equipamentos. 
Ressalta-se que a empresa utiliza cinco categorias de acidentes na classificação do tipo de lesão pela área médica, porém se ocorrer uma condição que não se enquadre nos critérios utilizados, outras classificações são consideradas na descrição do tipo de lesão.

O quadro 01 apresenta resumidamente a descrição geral da lesão utilizada pela área médica da empresa na classificação de acidentes por tipo de lesão.

Quadro 01 - Tipo de Lesão dos Acidentes

\begin{tabular}{|l|l|}
\hline \multicolumn{1}{|c|}{ Tipo de Lesão } & \multicolumn{1}{|c|}{ Descrição geral da lesão } \\
\hline Corte & $\begin{array}{l}\text { É uma lesão causada por golpe, incisão ou talho com } \\
\text { instrumento cortante. }\end{array}$ \\
\hline Contusão & $\begin{array}{l}\text { É uma lesão traumática aguda, sem corte, decorrente de } \\
\text { trauma direto aos tecidos moles e que provoca dor e edema. }\end{array}$ \\
\hline Entorse & $\begin{array}{l}\text { É uma lesão traumática de uma articulação, com alongamento, } \\
\text { arrancamento ou rotura de um ou mais ligamentos, sem } \\
\text { deslocamento das superfícies articulares. }\end{array}$ \\
\hline Queimadura & $\begin{array}{l}\text { É uma lesão causada por efeito do fogo ou do calor na pele } \\
\text { e/ou em algum órgão. }\end{array}$ \\
\hline Amputação parcial de dedo & $\begin{array}{l}\text { É uma lesão que ocorre com remoção de uma extremidade do } \\
\text { corpo devido à ocorrência de um acidente. }\end{array}$ \\
\hline
\end{tabular}

Fonte: Dados do abatedouro (2015)

Conforme Quadro 01, verifica-se que o setor de medicina da empresa definiu a classificação dos tipos de lesão de acordo com os parâmetros da medicina.

Como o maior número de acidentes ocorreu com cortes, este item foi analisado para melhor entendimento e para serem feitas propostas de demandas de intervenções ergonômicas. Ressalta-se que posteriormente todos os tipos de lesões devem ser avaliados para que propostas de demandas de intervenções ergonômicas sejam feitas, pois na Figura 03 estão estratificados os 81 casos de acidentes por cortes. 
Figura 03 - Causadores de acidentes por cortes

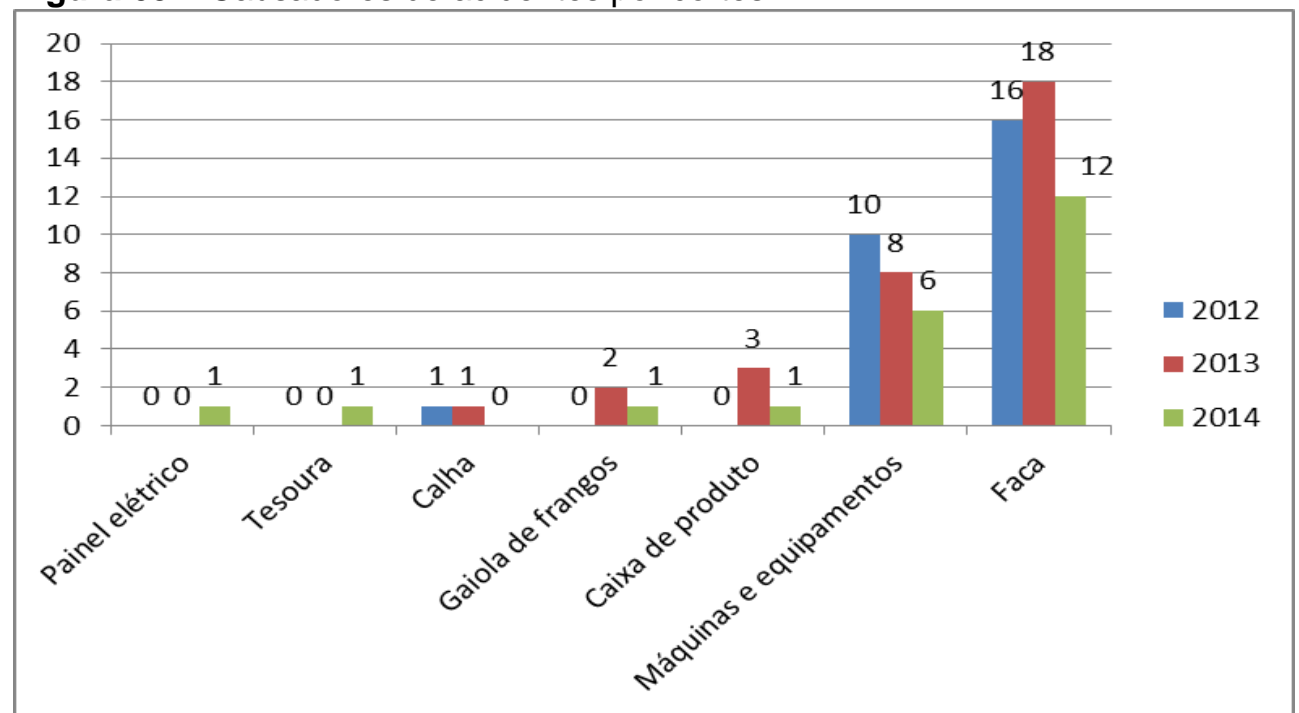

Fonte: Dados do abatedouro (2015)

Notam-se nos resultados apresentados na Figura 03 que predominaram os acidentes por cortes causados por uso da faca, com 46 ocorrências seguidas de 24 ocorrências de cortes causados por utilização de máquinas e equipamentos.

Seguindo a proposta do estudo, foram avaliadas as partes do corpo atingidas nos acidentes. Quanto a este item, o setor de medicina da empresa agrupou as partes do corpo para controle e acompanhamento dos acidentes. As partes do corpo agrupadas foram:

- cabeça e pescoço — inclui tudo que está acima da abertura torácica superior;

- membro superior - inclui a mão, antebraço, braço, ombro, axila, região peitoral e região escapular;

- tórax - é a região do peito compreendida entre a abertura torácica superior e o diafragma torácico;

- abdômen - é a parte do tronco entre o tórax e a pelve;

- costas - inclui a coluna vertebral e seus componentes, as vértebras e os discos intervertebrais;

- pelve e períneo - é a região de transição entre tronco e membros inferiores (pelve) e a região superficial entre sínfise púbica e cóccix (períneo); 
- membro inferior - geralmente é tudo que está abaixo do ligamento inguinal, incluindo a coxa, articulação do quadril, perna e pé.

A Figura 04 apresenta os resultados por partes do corpo atingidas nos acidentes durante os três anos analisados.

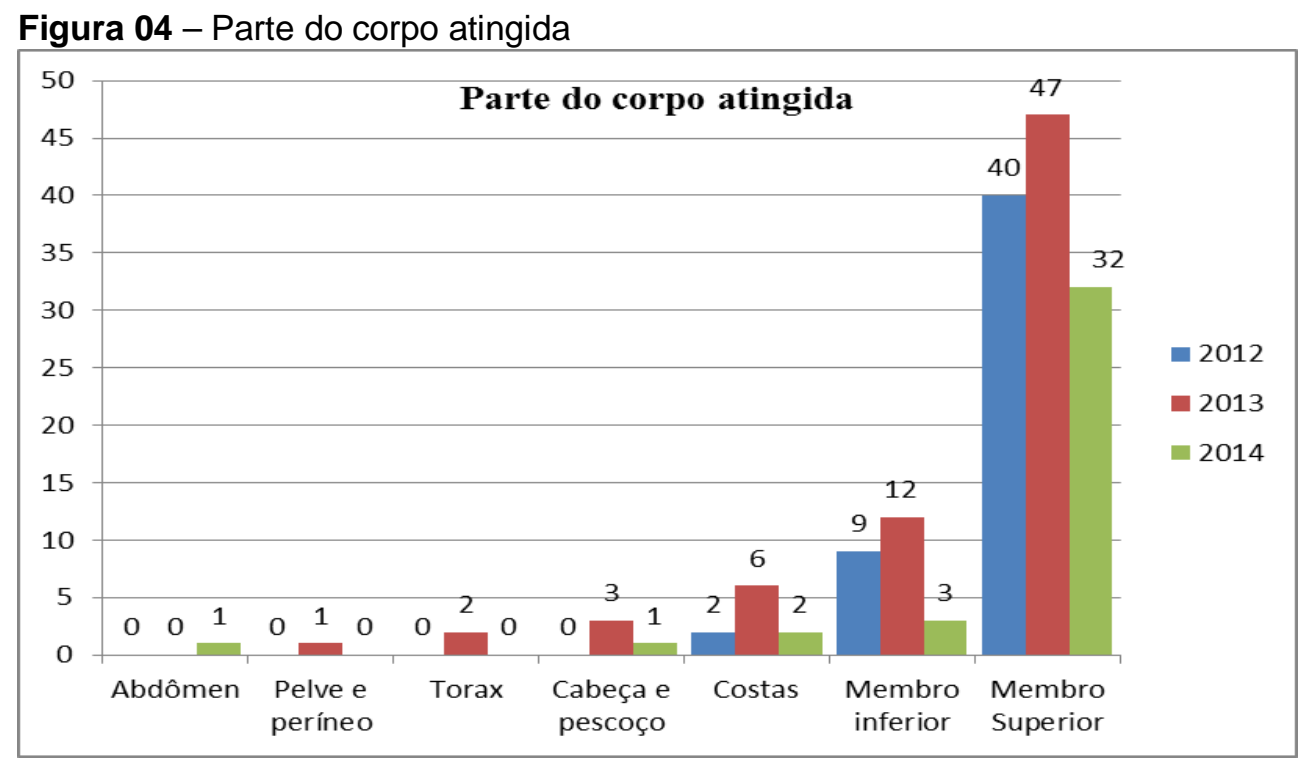

Fonte: Dados do abatedouro (2015)

Avaliando os dados apresentados na Figura 04, verifica-se que a parte do corpo mais atingida foi os membros superiores com 119 acidentes, seguida de 24 acidentes nos membros inferiores, 10 acidentes nas costas, 4 acidentes na cabeça $e$ pescoço, 2 acidentes no tórax, 1 acidente na pelve e períneo e 1 acidente no abdômen.

Outros dados coletados e tabulados no estudo foram os agentes que causaram os acidentes de trabalho conforme registro avaliado na pesquisa. Os resultados desses dados estão apresentados na Figura 05. 
Figura 05 - Agente do acidente

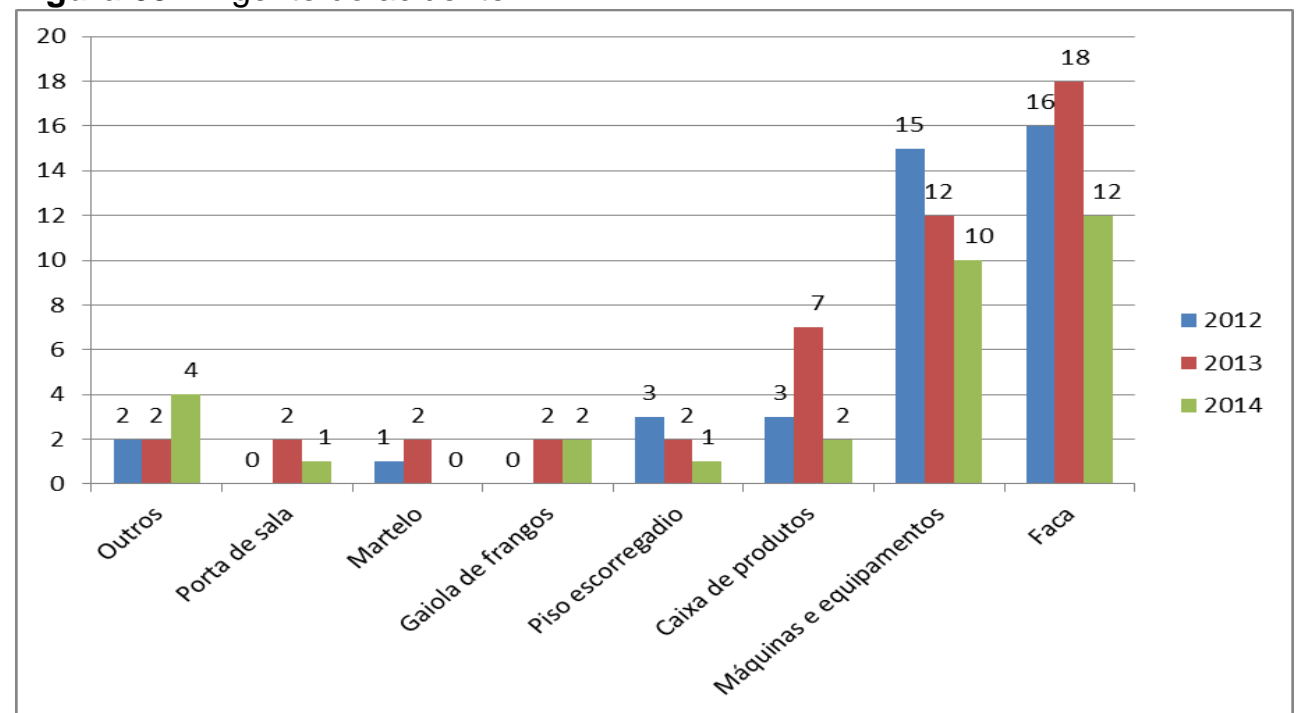

Fonte: Dados do abatedouro (2015)

Verifica-se na Figura 05 que o maior número de acidentes ocorreu com o agente causador faca, com 46 ocorrências, seguido de acidentes com uso de máquinas e equipamentos com 37 ocorrências e em terceiro os acidentes com manuseio de caixas de produtos com 12 ocorrências. O indicador Outros foram acidentes que ocorreram com escada, calha, tesoura, porta de painel elétrico, lenha para caldeira e barra de ferro, que foram agrupados para melhor visualização.

\section{DISCUSSÃO DOS RESULTADOS}

Por meio dos resultados apresentados, torna-se evidente o elevado número de acidentes típicos reconhecidos pela empresa, o que sustenta a veridicidade dos dados estatísticos de abatedouros demonstrados nos anuários oficiais de acidentes de trabalho.

Desprezando a gravidade dos acidentes que é um fator de extrema importância, porém considerando o quantitativo de acidentes, verifica-se nos resultados um elevado número de acidentes ocorridos nos membros superiores com 119 casos diagnosticados.

Do total de 161 acidentes, os casos a serem destacados devido ao elevado número de ocorrências foram 81 acidentes causados por cortes, 46 acidentes causados por manuseio de facas no ambiente de trabalho e 37 acidentes causados 
pelo uso de máquinas e equipamentos, sendo que seis destes acidentes causados por máquinas e equipamentos resultaram em amputação parcial de dedo.

Considerando que um dos objetivos da ergonomia é a busca da adaptação dos trabalhadores ao posto de trabalho para atender aos requisitos de conforto, satisfação, bem estar, e segurança e saúde no trabalho, base deste estudo, verificase na análise dos dados de acidentes que há a necessidade de estudos ergonômicos na empresa em estudo, cujo foco é revelar as causas desses acidentes para que se possa propor ações que contribuirão na eliminação, neutralização ou redução dos acidentes.

Conforme os maiores índices apontados na pesquisa, inicialmente a demanda de intervenção ergonômica deve considerar os seguintes fatos:

- acidentes com o manuseio de facas e com uso de máquinas e equipamentos representaram juntos $51,6 \%$ dos agentes causadores dos acidentes;

- $\quad$ os cortes e contusões representaram 82,4\% dos tipos de lesão;

- os acidentes que ocorreram nos membros superiores representaram $73,9 \%$ da parte do corpo mais atingida.

Ressalta-se que as demandas de intervenções ergonômicas descritas se tratam de uma proposta para iniciar as avaliações considerando os maiores índices apresentados na pesquisa, ou seja, as demais condições levantadas também devem posteriormente ser analisadas com o intuito de reduzir ao máximo as condições de riscos existentes em processos de abate e processamento de carnes.

Além disto, fica claro que as condições levantadas nas investigações realizadas pela equipe de prevenção de riscos e doenças são condições que não apresentam vínculo entre ergonomia e a prevenção de riscos de acidentes, pois a prevenção demonstra não ser eficiente com os métodos atualmente utilizados. Verifica-se ainda, que as condições apresentadas são denominadas de riscos "visíveis", ou seja, aqueles que causam danos ao corpo, como máquinas e equipamentos, evidenciados nas Figuras 03 e 05 como agentes causadores de acidentes. Por outro lado, os riscos denominados "virtuais", como por exemplo a sobrecarga e ritmo intenso de trabalho entre outros, não são demonstrados nos resultados apresentados, porém, quando existentes, também devem ser analisados 
para o tratamento das possíveis causas que levam a um acidente. Ressalta-se que estas condições "virtuais" foram descritas no referencial teórico desta pesquisa.

Para reforçar, nota-se que as condições apresentas nos dados analisados mostram apenas os agravos à saúde relativos à integridade corporal, conforme Figura 02 - Tipo de lesão dos acidentes por ano de ocorrência e Figura 04 - Parte do corpo atingida.

As condições apresentadas nas análises dos acidentes levam a considerar apenas um ou poucos fatores que podem causar um acidente ocasionando em abordagens de prevenção simplistas, a adoção de medidas de controle no comportamento das pessoas ou de ações pontuais nas máquinas ou equipamentos.

Salienta-se que um acidente de trabalho na maioria dos casos é causado por uma condição multicausal, ou seja, é necessário analisar as diversas condições que contribuem na ocorrência de um acidente no desenvolvimento de uma atividade de trabalho entre estas condições, podemos citar alguns exemplos que podem ocorrer na empresa avaliada neste estudo:

- a organização do trabalho: jornadas de trabalho sem adequação das pausas, escalas de trabalhos, equipes com quadro de trabalhadores insuficiente à demanda de trabalho, normas, procedimentos, entre outros;

- a pessoa e todos os seus recursos nos quais devem consideradas experiências, competências, habilidades, entre outros fatores pessoais;

- o sistema técnico e o ambiente de trabalho que devem levar em conta as matérias primas utilizadas no processo, as condições físicas, o nível de tecnologia empregado no processo produtivo, entre outros.

Fica evidente que os resultados analisados nas investigações da empresa em estudo não contribuem de forma significativa para o controle dos riscos a forma como os dados oriundos das investigações de acidentes são demonstrados não apresenta uma análise das condições que podem causar um acidente de trabalho e sim apenas o fator que contribuiu para a ocorrência do acidente.

Uma vez que o objetivo desta pesquisa é avaliar os indicadores de acidentes para demonstrar a necessidade de se propor demandas de intervenções ergonômicas para eliminação, neutralização ou minimização dos riscos de acidentes 
e doenças, o próximo tópico do trabalho irá abordar propostas de intervenções ergonômicas vinculando a ergonomia com a prevenção de riscos de acidentes com o intuito de contribuir no levantamento de todas as possíveis causas que levam a um acidente de trabalho.

\subsection{Propostas de Intervenções Ergonômicas}

Para as intervenções ergonômicas não serem tratadas superficialmente acarretando em resultados não satisfatórios, pois lidar com prevenção requer abordagens objetivas e subjetivas, uma proposta deste estudo é realizar a análise ergonômica do trabalho - AET, que na visão de Fialho e Santos (1997), é entendida como uma metodologia que tem como finalidade desvendar as diferenças entre os trabalhos formal e real com a intenção de elaborar recomendações de modificações das condições laborais em seus pontos críticos evidenciados de modo a possibilitar oportunidade à segurança e à eficácia de trabalhadores e processos, preservando a saúde e o conforto dos indivíduos. Ferreira et al. (2014) relatam em sua pesquisa que uma das formas de solucionar os problemas decorrentes da situação de trabalho transformada pela mecanização é através da utilização de instrumentos de análise ergonômica.

De acordo com lida (2005), o método da AET desdobra-se em cinco etapas, sendo: análise da demanda; análise da tarefa; análise da atividade; diagnóstico e recomendações.

A análise da demanda é a etapa inicial da metodologia AET que procura entender a natureza e a dimensão dos problemas apresentados. Considerando a necessidade de se estabelecer uma demanda para o estudo, foram propostos dois conjuntos de condições de acordo com os resultados encontrados.

O primeiro conjunto proposto para avaliação de uma intervenção ergonômica através da AET é com relação ao uso de facas e condições posturais dos membros superiores, condições estas que podem causar cortes e contusões. Descrição da Demanda: alto índice de cortes e contusões nos membros superiores com o uso de facas.

Revista Produção Online, Florianópolis, SC, v.16, n. 1, p. 182-209, jan./mar. 2016. 
O segundo conjunto de é o uso de máquinas e equipamentos e condições posturais dos membros superiores, condições estas que podem causar cortes, contusões e amputamentos. Descrição da Demanda: amputações e acidentes envolvendo membros superiores na operação de máquinas e equipamentos.

Estas demandas devem ser analisadas em todos os postos de trabalho, considerando as particularidades de cada local e também dos trabalhadores.

Consecutivamente, após realizar as intervenções ergonômicas nestes dois conjuntos, os demais itens devem ser analisados para que a eliminação dos riscos de acidentes seja proposta, pois toda possibilidade de acidente deve ser analisada e avaliada com o objetivo de ser eliminada ou neutralizada.

Considerando que os conjuntos sugeridos para a aplicação da AET envolvem equipamentos, posturas e condições de trabalho, verifica-se a necessidade de a intervenção avaliar os aspectos físicos de antropometria, fisiologia, biomecânica e características da anatomia humana bem como os aspectos cognitivos de percepção, memória, processamento de informações, tomadas de decisões e também os aspectos organizacionais de sistemas sócio técnicos, estrutura organizacional, politicas de gestão, organização do trabalho e cultura organizacional.

\subsection{Indicadores Específicos e a Intervenção Associada/Recomendada}

A cada ocorrência de um acidente de trabalho, a investigação e análise das causas devem ser realizadas de acordo com a proposta de intervenção ergonômica descrita a seguir.

Para melhor visualização da condição atual dos dados da empresa na qual é possível demonstrar a falta de vínculo entre ergonomia e prevenção de acidentes, o Quadro 02 apresenta os dados disponíveis em dois casos de acidentes fornecidos aleatoriamente com o intuito de demonstrar a condição atual de como as informações são tratadas no levantamento de um acidente por parte da equipe de prevenção de acidentes da empresa em estudo. 
Quadro 02 - Dados da investigação de acidentes de trabalho

\begin{tabular}{|c|c|c|c|c|c|}
\hline Setor & $\begin{array}{c}\text { Tipo de } \\
\text { acidente }\end{array}$ & $\begin{array}{c}\text { Tipo de } \\
\text { Lesão }\end{array}$ & $\begin{array}{c}\text { Agente } \\
\text { Causador }\end{array}$ & $\begin{array}{c}\text { Parte } \\
\text { atingida }\end{array}$ & Ações tomadas \\
\hline $\begin{array}{c}\text { Mesa da } \\
\text { Asa }\end{array}$ & Típico & Corte & Faca & $\begin{array}{c}\text { Pdvertência devido a } \\
\text { dedo da } \\
\text { mão direita. } \\
\text { ato inseguro de não } \\
\text { usar o Equipamento } \\
\text { de Proteção } \\
\text { Individual - EPI e re- } \\
\text { treinamento para uso } \\
\text { de EPIs para } \\
\text { atividade }\end{array}$ \\
\hline $\begin{array}{c}\text { Setor de } \\
\text { embalagens }\end{array}$ & Típico & Contusão & Piso & $\begin{array}{c}\text { Joelho da } \\
\text { perna } \\
\text { escorregadiorda }\end{array}$ & $\begin{array}{c}\text { Treinamento para } \\
\text { orientar a forma } \\
\text { adequada de } \\
\text { transitar no interior } \\
\text { da fábrica. }\end{array}$ \\
\hline
\end{tabular}

Fonte: Dados do abatedouro (2015)

O Quadro 02 demonstra que as ações tomadas são direcionadas apenas a uma causa conforme relatado nos resultados desta pesquisa, e que o acidente é tratado como um simples produto de uma dada causa específica. Com os resultados quantitativos de acidentes e as evidências demonstradas nos dados apresentados na investigação de acidentes, pode-se afirmar que os acidentes tendem a continuar acontecendo, pois as ações pontuais a uma única causa não são suficientes para eliminar, reduzir ou minimizar os casos de acidentes. Questiona-se então: Qual a certeza que se pode ter de que no primeiro caso a pessoa foi advertida por não estar usando a luva de proteção? Inúmeras condições para que o trabalhador não use a luva podem ser citadas, tal como: luva maior ou menor que sua mão, falta de habilidade quando utiliza a luva, esquecimento do trabalhador em retirar sua luva do local de guarda antes de iniciar as atividades, entre outros. Ressalta-se ainda outros dados apresentados na investigação e não necessários para a pesquisa em questão, tais como: sexo, tempo de serviço, data de início na empresa, hora do acidente, data do acidente, dias de afastamento devido ao acidente, chefia e tipo de acidente que é caracterizado por ato ou condição insegura. Ou seja, dados que são 
utilizados estatisticamente na empresa para gerenciar simplesmente os números de acidentes.

É necessária a aplicação de uma abordagem sistêmica para que se obtenham resultados positivos, na qual a investigação do acidente considere aspectos de ergonomia física, cognitiva e organizacional.

Como existe um elevado número de ferramentas de investigação de riscos, mas que demandam serem adaptadas para cada caso ou empresa, optou-se neste estudo não indicação de uma específica para levantamento das causas. Contudo, a investigação de acidente deverá responder as questões elencadas no Quadro 03.

Quadro 03 - Aspectos ergonômicos na ocorrência de um acidente

\begin{tabular}{|c|c|}
\hline $\begin{array}{l}\text { Aspectos } \\
\text { ergonômicos }\end{array}$ & $\begin{array}{l}\text { Levantamento dos dados conforme tarefa a ser executada e } \\
\text { atividade executada na ocorrência de um acidente }\end{array}$ \\
\hline \multirow[t]{5}{*}{ Ergonomia Física } & Descreva os aspectos anatômicos necessários na atividade. \\
\hline & Descreva os aspectos antropométricos necessários na atividade. \\
\hline & Descreva os aspectos fisiológicos necessários na atividade. \\
\hline & Descreva os aspectos biomecânicos necessários na atividade. \\
\hline & Descreva os riscos ambientais existentes na atividade. \\
\hline \multirow{7}{*}{$\begin{array}{l}\text { Ergonomia } \\
\text { Cognitiva }\end{array}$} & Qual a competência necessária para executar a atividade? \\
\hline & A atividade necessita de conhecimento especifico? \\
\hline & A atividade necessita de habilidades? Quais? \\
\hline & A atividade necessita de experiência? Quanto tempo? \\
\hline & A atividade é considerada estressante? Descreva. \\
\hline & A atividade necessita de raciocínio? Descreva. \\
\hline & A atividade necessita de atenção? Descreva. \\
\hline $\begin{array}{l}\text { Ergonomia } \\
\text { Cognitiva }\end{array}$ & A atividade necessita de treinamento? Qual ou quais? \\
\hline \multirow{4}{*}{$\begin{array}{l}\text { Ergonomia } \\
\text { Organizacional }\end{array}$} & Na atividade há rodízios? Descreva. \\
\hline & Existem pausas na atividade? Descreva. \\
\hline & Como a atividade é organizada? Descreva. \\
\hline & Existe politica de gestão na atividade? Descreva \\
\hline
\end{tabular}

Fonte: Dados da pesquisa (2015) 
O levantamento de riscos deverá responder as questões elencadas no Quadro 03 citando qual a condição necessária conforme a tarefa a ser executada e como estava sendo executada a atividade no momento do acidente para que se possam levantar todas as possíveis causas que levaram à ocorrência do acidente. No primeiro caso, por exemplo, podem ser citados alguns itens que poderiam ser abordados no levantamento das causas, sendo eles: qual luva foi disponibilizada e se era adequada ao tamanho da mão do trabalhador? A tarefa exigia habilidades e treinamentos para ser executada? O trabalhador atendia à condição de habilidades e treinamentos? A tarefa exigia atenção contínua? Qual era a condição de estresse em que o trabalhador encontrava-se no momento ou dia do acidente? Os exemplos citados podem levar a diversas causas que juntas contribuem na ocorrência de um acidente.

Todos os aspectos ergonômicos devem ser avaliados, pois quando não se conhece as causas e condições em que um trabalhador sofreu o acidente, há possibilidades de que o acidente volte a ocorrer com o mesmo trabalhador ou com outro que apresente características semelhantes.

O método sugerido baseia-se na $\mathrm{AET}$, no qual a problemática apontada pela demanda é a frequente ocorrência de acidentes. Posteriormente, com o levantamento de dados, é realizada a análise da tarefa e a análise da atividade, no entanto estas etapas devem ser fundamentadas na ergonomia física, cognitiva e organizacional. Por fim, baseando-se nas demais etapas da AET, pode-se realizar o diagnóstico e a elaboração do caderno de recomendações ergonômicas.

\section{CONSIDERAÇÕES FINAIS}

Conclui-se primeiramente que a evolução dos acidentes na empresa não toma forma padronizada, sendo que, mesmo levando em consideração o aumento de funcionários de um ano em relação a outro, as técnicas de segurança e medicina deveriam garantir o controle de acidentes, porém, não é o que ocorre na empresa. Tal condição reforça que as ações implantadas por parte da equipe de prevenção não surtem os efeitos esperados, pois acidentes pelas mesmas causas levantadas continuam acontecendo. 
Com relação ao ambiente de trabalho, nota-se a necessidade de intervenções ergonômicas com foco nas máquinas, ferramentas e equipamentos enfatizando a intervenção ergonômica no manuseio de facas e materiais cortantes utilizados na execução das atividades. Com relação aos trabalhadores, a intervenção ergonômica deve analisar inicialmente as atividades verificando os riscos para membros superiores, pois conforme os resultados encontrados no estudo, demonstram ser a parte do corpo mais atingida nos acidentes.

Para as ocorrências de acidentes é proposto um modelo de levantamento de dados da tarefa e da atividade no qual é possível sair da condição de análise da causa de apenas um agente de risco específico para um levantamento de dados conforme condições físicas, cognitivas e organizacionais que podem ser consideradas inadequadas do ponto de vista da tarefa e da atividade e que contribuem na ocorrência de um acidente.

Vale ressaltar que o modelo de levantamento de dados não garante que os acidentes não ocorram mais com outros trabalhadores, principalmente por que será analisado do ponto de vista pessoal. Os acidentes com os mesmos trabalhadores poderão ser evitados quando se conhecerem as restrições pessoais. Em contrapartida, mesmo que os resultados apresentem uma contribuição com maior ênfase na condição individual do que na condição coletiva, nota-se que poderá ser utilizada no coletivo conforme necessidades específicas em tarefas que podem ser aperfeiçoadas. Um exemplo é uma atividade que demanda treinamento específico para ser executada, a qual poderá ser realizada apenas por trabalhadores treinados e capazes de desenvolvê-la.

Portanto, a implantação da análise com abordagem na intervenção ergonômica deixa de influenciar o comportamento dos operadores e condições específicas de uma máquina ou equipamento para uma condição multicausal de efeitos que contribuem na ocorrência de acidentes.

O modelo apresentado não foi testado na empresa, pois demandaria acompanhamento de novos acidentes e o objetivo proposto da pesquisa foi avaliar os indicadores de acidentes para analisar a necessidade de demandas de intervenções ergonômicas para eliminação, neutralização ou minimização dos riscos de acidentes e doenças conforme o número de acidentes que ocorreram no período 
de três anos. Pode-se ressaltar que o objetivo foi alcançado devido a análise dos acidentes demonstrar sua ineficiência na solução das causas, o que pode ser completado com uma análise multicausal, possível de ser realizada com intervenções ergonômicas para condição geral. Cabe à empresa e similares avaliarem a necessidade e adaptarem o modelo proposto a sua realidade de trabalho.

Evidentemente nota-se nos resultados do estudo que o abatedouro apresenta demandas de intervenções ergonômicas para adequação das condições de trabalho com enfoque na redução de acidentes de trabalho. Um ambiente saudável e confortável para que os trabalhadores possam executar suas atividades é uma condição que pode ser alcançada com a aplicação de princípios de ergonomia, lembrando que tais princípios quando aplicados pelas empresas, estas não estão apenas cumprindo com a legislação trabalhista, mas também estão despertando em seus funcionários a importância de prevenção.

Por fim, estudos futuros são sugeridos para que abatedouros que se encontram em fase de instalação, utilizem a ergonomia de concepção que está relacionada ao planejamento de máquinas, equipamentos, instrumentos e ambientes de trabalho antes de sua construção. Ainda para a condição atual das empresas que estão em funcionamento que seja abordada a ergonomia de correção conforme as necessidades levantadas na AET para melhorar as condições já existentes e a aplicação da ergonomia de conscientização que orienta os trabalhadores em relação aos riscos de acidentes existentes no ambiente de trabalho bem como sua prevenção.

\section{REFERÊNCIAS}

ARMSTRONG, J.; BUCKLE, P.; FINE, L.; HAGBERG, B. J.; KILBOM, A.; KUORINKA, I. A; SILVERSTEIN, A.; SJOGAARD, G.; VIIKARI-JUNTURA, E. A.; Conceptual model for workrelated neck and upper-limb musculoskeletal disorders. Scand J Work Environ Health, p. 73-84, 1993.

ASSOCIAÇÃO BRASILEIRA DE NORMAS TÉCNICAS. NBR 14280: Cadastro de acidente do trabalho - Procedimento e classificação. Rio de Janeiro: ABNT, 2001.

BAO, S.; SILVERSTEIN, B.; COHEN, M. An electromyography study in three high risk poultry processing jobs. International Journal Of Industrial Ergonomics, [s.I.], v. 27, n. 6, p.375-385, jun. 2001. Elsevier BV. http://dx.doi.org/10.1016/s0169-8141(01)00004-x 
BUSNELLO, G. F.; DEWES, M. Doenças Osteomusculares Relacionadas às Atividades de Trabalhadores de Frigoríficos de Frangos. Brazilian Journal Of Surgery And Clinical Research - Bjscr, Maringá, v. 4, n. 3, p.27-32, 9 set. 2013. Trimestral. Disponível em: <http://www.mastereditora.com.br/bjscr>. Acesso em: 15 jun. 2015.

CAMPOAMOR, M. Estudo da Ocorrência de Acidentes entre Trabalhadores de uma Indústria Frigorífica do Estado de São Paulo. 2006. 97 f. Dissertação (Mestrado) - Curso de Programa de Pós Graduação em Enfermagem, Enfermagem, Escola de Enfermagem de Ribeirão Preto da Universidade de São Paulo, Ribeirão Preto, 2006.

CARPES JR, W. P.; SELL, I. O PRODUTO COMO CAUSADOR DE ACIDENTES. Revista Po: R. Eletr. de Eng. de Produção e Correlatas, [s.I.], v. 4, n. 2, p.1-19, 10 jun. 2004. Associação Brasileira de Engenharia de Produção - ABEPRO. http://dx.doi.org/10.14488/1676-1901.v4i2.305

\begin{abstract}
DEFANI, J. C. Avaliação do Perfil Antropométrico e Análise Dinamométrica dos Trabalhadores da Agroindústria do Setor de Frigoríficos e Abadedouros: O Caso da Perdigão - Carambeí. 2007. 143 f. Dissertação (Mestrado) - Curso de Pós Graduação em Engenharia de Produção, Programa de Pós Graduação em Engenharia de Produção, Universidade Tecnológica Federal do Paraná, Ponta Grossa, 2007.
\end{abstract}

FERREIRA, A. L. R., et al. Seleção de pontos de verificação do instrumento ergonomic checkpoints in agriculture para o processo de colheita mecanizada da cana-deaçúcar. Revista Po: R. Eletr. de Eng. de Produção e Correlatas, [s.I.], v. 14, n. 4, p.15371557, 14 abr. 2014. Associação Brasileira de Engenharia de Produção - ABEPRO. http://dx.doi.org/10.14488/1676-1901.v14i4.1724

FROST, P.; ANDERSEN, J. H.; NIELSEN, Vk. Occurrence of carpal tunnel syndrome among slaughterhouse workers. Scand J Work Environ Health, [s.I.], v. 24, n. 4, p.285-292, ago. 1998. Scandinavian Journal of Work, Environment and Health. http://dx.doi.org/10.5271/sjweh.322

GIL, A. C. Como elaborar projetos de pesquisa. São Paulo: Atlas, 1989.

HECK, F. M. Uma geografia da degradação do trabalho: o adoecimento dos trabalhadores em frigoríficos. Revista Percurso - NEMO. Maringá, v. 5, n. 1, p. 03- 31, 2013.

IIDA, I. Ergonomia: projeto e produção. 2. ed. São Paulo: Bluscher, 2005. 614 p.

INSTITUTO BRASILEIRO DE GEOGRAFIA E ESTATÍSTICA. Base de dados agregados (SIDRA) Pesquisa Trimestral do Abate de Animais (2013). Disponível em: $<\mathrm{http}: / /$ www.sidra.ibge.gov.br/bda/tabela/listabl.asp?c=1093\&z=t\&o=24>. Acesso em: 04/02/2015.

JUUL-KRISTENSEN, B et al. Physical workload during manual and mechanical deboning of poultry. International Journal Of Industrial Ergonomics, [s.I.], v. 29, n. 2, p.107-115, fev. 2002. Elsevier BV. http://dx.doi.org/10.1016/s0169-8141(01)00051-8

LAKATOS, E. M.; MARCONI, M. A. Técnicas de pesquisa. São Paulo: Atlas, 2007.

LEI NN 8.213 DE 24 DE JULHO DE 1991. Dispõe sobre os Planos de Benefícios da Previdência Social e dá outras providências. Disponível em: < http://www.planalto.gov.br/ccivil_03/leis/l8213cons.htm> Acesso em: 02/03/2015.

Revista Produção Online, Florianópolis, SC, v.16, n. 1, p. 182-209, jan./mar. 2016. 
MARRA, G. C.; SOUZA, L. H.; CARDOSO, T. A. O. Biossegurança no trabalho em frigoríficos: da margem do lucro à margem da segurança. Ciênc. saúde coletiva [online]. 2013, vol.18, n.11, pp. 3259-3271.

MINISTÉRIO DA PREVIDÊNCIA SOCIAL. Anuário Estatístico de Acidentes de Trabalho - AEAT Infologo (base de dados históricos de acidentes de trabalho). Disponível em: $<$ http://www3.dataprev.gov.br/aeat/> Acesso em: 02/03/2015.

MINISTÉRIO DO TRABALHO E EMPREGO. Relação Anual de Informações Sociais. Disponível em: < http://portal.mte.gov.br/rais/estatisticas.htm> Acesso em: 02/03/2015.

MUSOLIN, Kristin et al. Prevalence of carpal tunnel syndrome among employees at a poultry processing plant. Applied Ergonomics, [s.I.], v. 45, n. 6, p.1377-1383, nov. 2014. Elsevier BV. http://dx.doi.org/10.1016/.apergo.2014.03.005

MINISTÉRIO DO TRABALHO E EMPREGO. NR 17: Ergonomia. Brasil, 2015. 14 p. Disponível em:

http://portal.mte.gov.br/data/files/FF8080812BE914E6012BEFBAD7064803/nr_17.pdf>. Acesso em: 20 abr. 2015.

MINISTÉRIO DO TRABALHO E EMPREGO. NR 36: Segurança e Saúde no Trabalho em Empresas de Abate e Processamento de Carnes e Derivados. Brasil, 2015. 19 p. Disponível em: <http://portal.mte.gov.br/data/files/8A7C812D3DCADFC3013E237DCD6635C2/NR-36 (atualizada 2013).pdf>. Acesso em: 20 abr. 2015.

OIT - Organização Internacional do Trabalho. Introductory report: decent work - safe work. Anais do 27th World Congress on Safety and Health at Work. Orlando, 2005. Disponível em http://www.ilo.org/public/libdoc/ilo/2005/105B09_281_engl.pdf. Acesso em 10/02/2015.

PEGATIN, T. O. Estratégia para análise de efeitos dos curtos tempos de ciclo na funcionalidade de membros superiores em trabalhadores de atividades semiautomatizadas.2009. 104 f. Dissertação (Mestrado) - Curso de Engenharia de Produção, Departamento de Pós Graduação em Engenharia de Produção, Universidade Tecnológica Federal do Paraná, Ponta Grossa, 2009. Disponível em: <http://www.pg.utfpr.edu.br>. Acesso em: 28 mar. 2015.

REIS, P. F. O trabalho repetitivo em frigorífico: utilização da estesiometria da mão como proposta para avaliação dos níveis de LER/DORT nas síndromes compressivas dos membros superiores. 2012. 181 f. Tese (Doutorado) - Curso de Engenharia de Produção, Centro Tecnológico, Universidade Federal de Santa Catarina, Florianópolis, 2012. Disponível em: <http://ppgep.ufsc.br/>. Acesso em: 28 mar. 2015.

SANTOS, N.; FIALHO, F. Manual de análise ergonômica no trabalho. Curitiba: Gênesis Editora, $2^{\circ}$ edição; 1997.

SARDA, S. E.; RUIZ, R. R.; KIRTSCHIG, G. A tutela jurídica da saúde dos empregados de frigoríficos: considerações dos serviços públicos. Acta Fisiatr. v. 16, n. 2, p. 59-65, 2009.

SILVEIRA, A. L.; MERLO, A. R. C. O caso dos frigoríficos: contribuições da fenomenologia existencialista e da psicodinâmica do trabalho para refletir sobre a deficiência física

adquirida. Cadernos Brasileiros de Saúde Mental. Florianópolis, v.6, n.13, p.1-20, 2014. Revista Produção Online, Florianópolis, SC, v.16, n. 1, p. 182-209, jan./mar. 2016. 
SOUZA, M. N. A., et al. Fatores ergonômicos, psicossociais e riscos no trabalho na mineração informal. Revista Po: R. Eletr. de Eng. de Produção e Correlatas, [s.I.], v. 15, n. 3, p. 1099-1120, jul/set. 2015. Associação Brasileira de Engenharia de Produção ABEPRO. http://dx.doi.org/10.14488/1676-1901.v15i3.2018

SOMMERICH, C. M.; MCGLOTHLIN, J. D.; MARRAS, W. S. Occupational risk factors associated with soft tissue disorders of the shoulder: a review of recent investigations in the literature. Ergonomics, [s.I.], v. 36, n. 6, p.697-717, jun. 1993. Informa UK Limited. http://dx.doi.org/10.1080/00140139308967931

SUNDSTRUP, E., et al. Participatory ergonomic intervention versus strength training on chronic pain and work disability in slaughterhouse workers: study protocol for a single-blind, randomized controlled trial. Bmc Musculoskeletal Disorders, [s.I.], v. 14, n. 1, p.67-79, 2013. Springer Science + Business Media. http://dx.doi.org/10.1186/1471-2474-14-67

SUNDSTRUP, E., et al. High Intensity Physical Exercise and Pain in the Neck and Upper Limb among Slaughterhouse Workers: Cross-Sectional Study. Hindawi Publishing Corporation: BioMed Research International. New York, p. 1-6. 09 jan. 2014. Disponível em: http://dx.doi.org/10.1155/2014/218546

VILELA, R. A. G.; ALMEIDA, I. M.; MENDES, R. W. B. Da vigilância para prevenção de acidentes de trabalho: contribuição da ergonomia da atividade. Ciência \& Saúde Coletiva, São Paulo, v. 17, n. 10, p.2817-2830, out. 2012. Mensal. CD-ROM.

WISNER, A. Le diagnostic en ergonomie ou le choix des modeles operantes en situation reelle de travail; Rapport $n^{\circ}$ 28; Paris; Misitere de L'education Nationale, 1972.

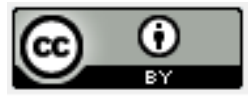

Artigo recebido em 06/07/2015 e aceito para publicação em 31/10/2015

DOI: $\underline{\text { http://dx.doi.org/ 10.14488/1676-1901.v16i1.2075 }}$ 